\title{
Nicotine Induces Glutamate Release from Thalamocortical Terminals in Prefrontal Cortex
}

\author{
Evelyn K Lambe*,', Marina R Picciotto' and George K Aghajanian' \\ 'Departments of Psychiatry and Pharmacology, Yale School of Medicine, New Haven, CT, USA
}

\begin{abstract}
It has been proposed that activation of nicotinic acetylcholine receptors ( $\mathrm{nAChRs)}$ can activate the prefrontal cortex, enhancing attention and cognition. Nicotine can stimulate the release of several different neurotransmitters in many brain regions. In the present study, we found that stimulation of $\mathrm{nAChRs}$ by nicotine or the endogenous agonist, acetylcholine (ACh), induces a large spontaneous increase in glutamate release onto layer $V$ pyramidal neurons of the prefrontal cortex. This release of glutamate, measured by spontaneous excitatory postsynaptic currents (sEPSCs) in the prefrontal cortical slice, depends on intact thalamocortical terminals. It can be suppressed by $\mu$-opioids or eliminated by blocking action potentials. The increase in sEPSCs is sensitive to low concentrations of nicotine, suggesting the involvement of high-affinity (eg $\left.\alpha_{4} \beta_{2}\right) n A C h R s$. Recent work has shown alterations in prefrontal $\alpha_{4} \beta_{2} n A C h R s$ in autism and schizophrenia, two conditions that are distinguished by abnormal prefrontal cortical activation as well as difficulty in certain aspects of cognition and integrating social and emotional cues. We show that mice lacking the $\beta_{2}$ nAChR subunit do not show increased sEPSCs with either nicotine or ACh, again implicating high-affinity nicotinic receptors. These findings give new insight into the mechanism by which nicotine affects excitatory neurotransmission to the output neurons of the cerebral cortex in a pathway that is critical for cognitive function and reward expectation.

Neuropsychopharmacology (2003) 28, 216 -225. doi: I 0. I 038/sj.npp. 1300032
\end{abstract}

Keywords: high-affinity nicotinic acetylcholine receptors; rat; knockout mouse; spontaneous EPSCs; lesion; ectopic action potentials

\section{INTRODUCTION}

Nicotine has been shown to activate the prefrontal cortex and have positive effects on tasks of attention and cognitive processing (Levin and Simon, 1998; Stein et al, 1998; Dani, 2001). One mechanism underlying this activation could be the enhancement of glutamate release in the prefrontal cortex by heterosynaptic nicotinic acetylcholine receptors (nAChRs). It has been shown that electrical activity in thalamocortical projections to superficial layers of the cortex can be enhanced by nicotine (Vidal and Changeux, 1993; Gil et al, 1997; Gioanni et al, 1999); however, the effects of nAChR stimulation on glutamate release have not previously been examined in layer $\mathrm{V}$, the principal output layer of the cortex. Recently, in connection with a study on the mechanism of serotonin-induced glutamate release from thalamocortical terminals (Lambe and Aghajanian, 2001), we observed that nicotine produced a marked increase in spontaneous glutamate release onto layer V pyramidal cells,

*Correspondence: EK Lambe, Ribicoff Research Facilities, Rm 307, CMHC, 34 Park Street, New Haven, CT 06508, USA, Tel: + I 203974 777I, Fax: + I 203974 7897, E-mail: evelyn.lambe@yaleedu

Received I 8 March 2002; revised I 3 June 2002; accepted I I July 2002 which could also be induced by acetylcholine (ACh) in the presence of muscarinic blockade.

The purpose of this study is to examine the mechanism of nicotinic-induced glutamate release in the prefrontal cortex using pharmacological tools and a $\beta_{2}$ nAChR subunit knockout mouse to ascertain the subtype of nicotinic receptors involved. In particular, we wanted to determine whether nicotine and ACh are able to depolarize thalamocortical terminals in the prefrontal cortex sufficiently to induce action potentials directly in these terminals. It has long been recognized that such 'ectopic' or local terminal action potentials can be generated in thalamocortical projections (Gutnick and Prince, 1972; Rosen and Vastola, 1977; Noebels and Prince, 1978; Pinault and Pumain, 1989; Pinault, 1990, 1995). Under certain conditions, this phenomenon has been implicated in the generation of focal seizures (Gutnick and Prince, 1972; Schwartzkroin et al, 1975; Noebels and Prince, 1978; McCormick and Contreras, 2001), but under normal conditions may play a role in synchronization and strengthening of thalamocortical connections involved in normal learning and memory (Pinault, 1995). Terminal action potentials can be generated at a threshold more negative than that required for somatic action potentials (Stasheff et al, 1993), and can be induced when the soma is inhibited (Pinault, 1995) or 
after connection to the soma has been severed (Léna et al, 1993).

We found that application of nicotine resulted in an increase in glutamate release onto layer $\mathrm{V}$ pyramidal neurons, as measured by a dramatic increase in spontaneous excitatory postsynaptic currents (sEPSCs). It is important to mention that the frequency of sEPSCs recorded in the absence of tetrodotoxin (TTX) represents the sum of TTX-insensitive, miniature EPSCs (or mEPSCs) and TTX-sensitive (action-potential-dependent) EPSCs (Wong et al, 2000). There was reason to think that the nicotinic-induced increase in glutamate release might be the latter type of sEPSCs, those mediated by spiking, so we assessed the effects of blocking action potentials and highvoltage-activated calcium channels. Previous work suggested that the glutamate release may be selectively from thalamocortical nerve terminals (Prusky et al, 1987; Sahin et al, 1992; Lavine et al, 1997; Gioanni et al, 1999). We give evidence that it is virtually abolished by thalamic lesions. Furthermore, increased glutamate release could be induced by low concentrations of agonist, suggesting the involvement of high-affinity (eg $\left.\alpha_{4} \beta_{2}\right)$ nAChRs. The responsible nicotinic subunits were confirmed by examining the phenomenon in wild-type mice and mice lacking the $\beta_{2}$ nAChR subunit.

\section{METHODS}

\section{Preparation of the Prefrontal Cortical Slice}

Brain slices were prepared from 3 to 5-week-old male Sprague-Dawley albino rats, as well as 8 to 10 -week-old male wild-type or $\beta 2$ subunit knockout mice backcrossed 16 generations onto the $\mathrm{C} 57 \mathrm{Bl} / 6$ background (Picciotto et al, 1995), in adherence with protocols approved by the Yale University Animal Care and Use Committee. All efforts were made to minimize both the number of animals used and their suffering.

Briefly, the rats and mice were deeply anesthetized with chloral hydrate $(400 \mathrm{mg} / \mathrm{kg})$ and decapitated. Brains were quickly removed and blocked in ice-cold oxygenated modified artificial cerebrospinal fluid (ACSF) in which sucrose $(252 \mathrm{mM})$ is substituted for $\mathrm{NaCl}$. A $300 \mu \mathrm{m}$ thick coronal section was cut on a DSK microslicer (Dosaka EM, Japan) and transferred to the stage of a submerged recording chamber perfused with fast-flowing $(4 \mathrm{ml} / \mathrm{min})$, oxygenated, standard ACSF at room temperature; the slice was secured by a fine mesh attached to a platinum wire frame. After placement of the slice, the bath temperature was raised to $30^{\circ} \mathrm{C}$. With this fast flow rate, known concentrations of drugs dissolved in ACSF applied through a stopcock arrangement reached the slice within 7-10 s. Standard ACSF was composed of $126 \mathrm{mM} \mathrm{NaCl}, 3 \mathrm{mM} \mathrm{KCl}$, $1.25 \mathrm{mM} \mathrm{NaH} \mathrm{PO}_{4}, 10 \mathrm{mM}$ D-glucose, $25 \mathrm{mM} \mathrm{NaHCO}$, $2 \mathrm{mM} \mathrm{CaCl}_{2}$ and $2 \mathrm{mM} \mathrm{MgSO}_{4}(\mathrm{pH} \mathrm{7.35)}$.

\section{Whole-cell Recordings of sEPSCs in Prefrontal Pyramidal Neurons}

Medial prefrontal pyramidal cells were selected using an Olympus BX50WI $(\times 40$ IR lens, NA 0.8$)$ with infrared differential interference contrast (IR/DIC) microscopy
(Olympus, Melville, NY). Low-resistance patch pipettes (3-5 M $\Omega$ ) were pulled from Kovar glass tubing (WPI, Sarasota, FL) using a Brown and Flaming Horizontal Puller (Sutter Instruments, Novato, CA) and filled with the following pipette solution: $120 \mathrm{mM} \mathrm{K}$ gluconate, $10 \mathrm{mM}$ HEPES, $5 \mathrm{mM}$ BAPTA K4, $20 \mathrm{mM}$ sucrose, $2.38 \mathrm{mM} \mathrm{CaCl}$, $1 \mathrm{mM} \mathrm{MgCl}_{2}, 1 \mathrm{mM} \mathrm{Na} \mathrm{Na}_{2}$ TP and $0.1 \mathrm{mM}$ Tris-GTP (pH 7.33). Whole-cell recordings were made in current clamp (bridge) mode with an Axoclamp-2B amplifier (Axon Instruments, Foster City, CA) and yielded mean resting potential, spike amplitude, and input resistance values of $($ mean $\pm \mathrm{SE} ; n=65)-73.8 \pm 0.6 \mathrm{mV}, 110.0 \pm 1.3 \mathrm{mV}$ and $87 \pm 1.6 \mathrm{M} \Omega$ respectively.

Synaptic currents were recorded using continuous singleelectrode voltage clamp mode. Neurons were held at $\sim-75 \mathrm{mV}$, which is near the reversal potential for chloride under these conditions. Recordings were only included in these studies if the series resistance remained below $8 \mathrm{M} \Omega$. Spontaneously occurring sEPSCs were low-pass filtered at $3 \mathrm{kHz}$, amplified $100 \times$ through Cyberamp and digitized at $15 \mathrm{kHz}$, and acquired using pClamp/Digidata 1200 (Axon Instruments, Foster City, CA).

\section{Drug Application and sEPSC Recording Parameters}

Spontaneous EPSCs were recorded continuously during and immediately following drug applications so that the 10 -s peak period of sEPSCs could be detected. Nicotine- and ACh-induced sEPSCs commenced within 7-10s of application and reached a peak between 20 and $70 \mathrm{~s}$, depending on the concentration used. To avoid desensitization, ACh or nicotine was applied for no more than $45 \mathrm{~s}$ at a time. If nicotine applications were to be repeated, this lipophilic compound was applied at a low concentration for no more than $45 \mathrm{~s}$ followed by a lengthy washout time (minimum $30 \mathrm{~min}$ ) determined to allow a reproducible effect. Once the peak period was noted for a specific flow rate, the same measurement period was used for all cells included in a specific experiment. For analysis of sEPSC kinetics, we sampled 30 isolated single peaks of varying amplitudes from each condition. Time constants of decay were estimated by single exponential curve fitting. Drugs and toxins were applied in the fast-flowing bath. TTX $(2 \mu \mathrm{M})$ was applied for $5 \mathrm{~min}$ to block action-potential-dependent transmitter release before applying nicotine or ACh. A lower concentration of TTX was also used in additional experiments (200 nM; $10 \mathrm{~min})$. $\omega$-Agatoxin-IVA $(200 \mathrm{nM})$ was applied in the bath for $15 \mathrm{~min}$ before applying nicotine or ACh. LY239,558 $(3 \mu \mathrm{M})$ was applied for $3 \mathrm{~min}$ before applying nAChR agonists.

\section{Data Analysis}

Analysis of sEPSCs from each 10-s block of sweeps was performed using MiniAnalysis software (Synaptosoft Inc., Decatur, GA). This program detects and measures spontaneous synaptic events according to amplitude, rise time, decay time and area under the curve. As a result of high frequency of sEPSCs, the ability to measure overlapping or closely occurring peaks accurately is important for our analysis. The software uses an algorithm to detect multiple and complex peaks and automatically adjusts the baseline of 
closely occurring peaks using exponential extrapolation of decay. Amplitude and area thresholds were set to $8 \mathrm{pA}$ and 25-50 fC, respectively. Given our noise level of $\sim 5 \mathrm{pA}$, this combination of thresholds maximized correct identification of sEPSCs and minimized false positives. The significance of any treatment on sEPSC frequency was assessed with Kolmogorov-Smirnov analysis for each neuron (data from the peak $20 \mathrm{~s}$ compared to $20 \mathrm{~s}$ of baseline); $P<0.01$ was considered significant. Where described in text and figures, Student's $t$-tests were used to compare responses from several neurons (Prusky et al, 1987; Sahin et al, 1992; Lavine et al, 1997; Gioanni et al, 1999). Baseline levels of sEPSCs were similar in mean and range across groups of neurons, and analysis by one-way ANOVA across experimental groups revealed no significant effect of group (rats, lesioned rats, wild-type or knockout mice) on baseline sEPSCs. Since we were assessing the ability of nicotine or ACh to increase sEPSCs above baseline under various conditions, we have at times illustrated our results graphically as increase in EPSCs frequency', which was obtained by subtracting the baseline level of sEPSCs from the nAChR-induced peak of sEPSCs.

\section{Radiofrequency Lesions}

We followed the unilateral radiofrequency lesioning procedure described by Marek et al (2001). In brief, rats were deeply anesthetized with an intraperitoneal injection of $400 \mathrm{mg} / \mathrm{kg}$ chloral hydrate and placed in a stereotaxic apparatus. Upon removal of a small piece of skull, an electrode (with $2 \mathrm{~mm}$ of tip exposed) was lowered into the left anterior thalamus. The coordinates, in relation to Bregma, were $2.0 \mathrm{~mm}$ posterior, $1.0 \mathrm{~mm}$ lateral and $6.0 \mathrm{~mm}$ deep. We made a unilateral thalamic lesion by passing $20 \mathrm{~mA}$ of current for $60 \mathrm{~s}$ with a Grass LM4 radiofrequency lesion maker $(100 \mathrm{kHz})$. Sham lesioned rats received the same treatment, the electrode was lowered $1 \mathrm{~mm}$ short of the desired target and current was not passed. Animals were allowed a 10 to 14 day recovery period to allow the degeneration of thalamocortical projections. After the slice was placed in the recording chamber, the thalamus was blocked and sectioned to verify lesion placement and size. The lesions were reconstructed along medial-lateral, dorsoventral, and anterior-posterior dimensions using coronal sections from a rat brain atlas (Paxinos and Watson, 1986).

\section{Chemicals and Toxins}

TTX was from Alomone Labs (Jerusalem, Israel). LY293,558 was a gift from Eli Lilly. All other compounds, including nicotine, ACh, atropine, choline, 5-HT, [D-Ala ${ }^{2}, \mathrm{~N}-\mathrm{Me}-$ $\mathrm{Phe}^{4}, \mathrm{Gly}^{5}$-ol]-enkephalin (DAMGO), dihydro- $\beta$-erythroidine $(\mathrm{DH} \beta \mathrm{E})$ and $\omega$-agatoxin IVA, were from Sigma-RBI (St Louis, MO).

\section{RESULTS}

nAChR stimulation, either with nicotine or ACh (after muscarinic block with $0.5 \mu \mathrm{M}$ atropine), was found to induce a characteristic increase in sEPSCs in layer $\mathrm{V}$ pyramidal neurons, shown in Figure 1. Spontaneous EPSC frequency was significantly increased by low concentrations of nicotine $(300 \mathrm{nM})$ and acetylcholine $(100 \mu \mathrm{M})$, with larger increases at higher concentrations. These sEPSCs for nicotine and ACh showed respective 10-90\% rise times (mean $\pm \mathrm{SE}$ ) of $1.0 \pm 0.1$ and $1.1 \pm 0.1 \mathrm{~ms}$, as well as $63 \%$ decay times of $2.7 \pm 0.3$ and $2.8 \pm 0.3 \mathrm{~ms}$, which do not differ significantly from the rise and decay times of baseline sEPSCs: $1.1 \pm 0.1$ and $2.6 \pm 0.4 \mathrm{~ms}$ respectively (the sampling procedure is described in the Methods section). The sEPSCs induced by nicotine showed a prolonged plateau that extended beyond the application period, whereas sEPSCs induced by ACh ended more rapidly after bath application of the compound, as illustrated in Figure 2. A rapid desensitization (not shown) was observed during the application of higher concentrations of nicotine (30$100 \mu \mathrm{M})$ which precluded traditional dose-response analysis. Levels of nicotine $(10 \mu \mathrm{M})$ and $\mathrm{ACh}(3 \mathrm{mM})$ that gave consistent large increases in sEPSCs and manageable washout times were chosen for further experiments to characterize the mechanism and nAChR subunits involved. In some layer $\mathrm{V}$ pyramidal neurons, both nicotine and $\mathrm{ACh}$ produced a small outward or inward current, but this was variable and not correlated with the occurrence of sEPSCs.

Since it is not feasible to record from thalamocortical terminals directly, we assessed the action potential dependence of this phenomenon in two indirect ways: blocking fast sodium channels with TTX, as shown in Figure 3, and blocking high-voltage-activated calcium channels with $\omega$ agatoxin IVA. Spontaneous EPSCs induced by either nicotine or ACh could be suppressed by TTX $(2 \mu \mathrm{M}$, five neurons; $200 \mathrm{nM}$, one neuron): $-96 \pm 1$ and $-97 \pm 2 \%$, respectively. The small residual release (significant by Kolmogorov-Smirnov analysis in three out of six neurons) was congruent with the low level of miniature EPSCs previously described for $\alpha_{4} \beta_{2}$-mediated transmitter release in the presence of TTX (Léna and Changeux, 1997). Spontaneous EPSCs induced by both nicotine and ACh could also be suppressed by $\omega$-agatoxin IVA, at a concentration that preferentially blocks P-type calcium channels (200 nM, four neurons) (Sidach and Mintz, 2000): $-97 \pm 3$ and $-93 \pm 1 \%$, respectively.

Further support for our hypothesis that the increase in sEPSC frequency induced by $\mathrm{nAChR}$ stimulation represented an increase in the spike-dependent sEPSCs could be found in an analysis of basal and nAChR-induced sEPSC amplitude, as illustrated in Figure 3. The frequency of sEPSCs recorded in the absence of TTX represents the sum of TTX-insensitive miniature EPSCs and TTX-sensitive (action-potential-dependent) EPSCs (Wong et al, 2000). The latter component has been previously demonstrated to be of larger amplitude than the former in layer $\mathrm{V}$ cortical pyramidal neurons (Wong et al, 2000; Berretta and Jones, 1996). Since we hypothesized that the increase in sEPSC frequency induced by $\mathrm{nAChR}$ stimulation represented an increase in the spike-dependent component of the sEPSCs, we predicted that nAChR-induced sEPSCs would have a significantly higher amplitude than basal sEPSCs. This increase in amplitude is shown in Figure $3 \mathrm{~b}$ and was significant by Kolmogorov-Smirnov analysis in five of the six neurons.

On the postsynaptic side, the sEPSCs could be blocked by the glutamate AMPA/KA receptor antagonist, LY293558 ( $3 \mu \mathrm{M}$, five neurons): $-93 \pm 2$ and $-94 \pm 1 \%$, respectively. 

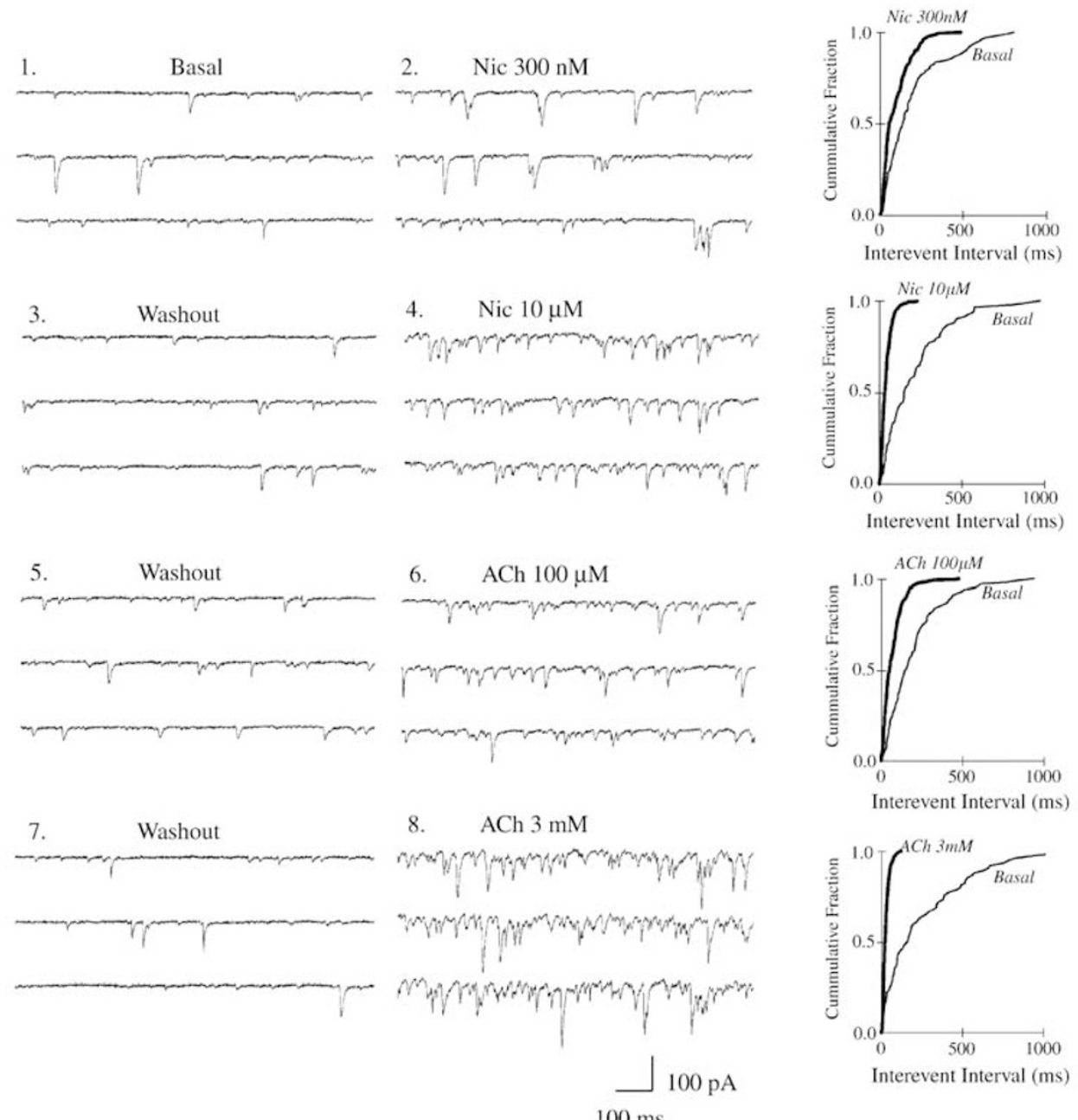

Figure I Nicotinic stimulation induces a robust increase in sEPSC frequency in layer $\vee$ pyramidal neurons of the prefrontal cortex. Recordings showing sEPSCs induced by different concentrations of nicotine and ACh (in the presence of atropine to block muscarinic receptors). Sweeps in voltage clamp from a representative neuron showing each concentration induced a significant increase in SEPSC frequency, as determined by Kolmogorov-Smirnov analysis $(P<0.000 \mathrm{I})$. On the left, cumulative fraction curves from this neuron for each concentration of nicotine or ACh.

Although, under certain conditions, nicotine has been shown to increase serotonin (5-HT) release in various brain areas (Li et al, 1998), nicotinic-induced sEPSCs in our slice preparation were not secondary to the release of endogenous serotonin by nAChRs, since the selective serotonin 5$\mathrm{HT}_{2 \mathrm{~A}}$ receptor antagonist, M100907 (which completely eliminates serotonin-induced sEPSCs (Aghajanian and Marek, 1997) had no effect on nicotinic-induced sEPSCs $(n=3)$.

\section{Effects of Thalamic Lesions}

Thalamocortical projections are known to contain nicotinic receptors (Gil et al, 1997), and thalamic lesions have been shown to markedly reduce nicotine binding in the midlayers of cortex (Prusky et al, 1987; Sahin et al, 1992; Lavine et al, 1997; Gioanni et al, 1999). In order to test the hypothesis that nicotine triggers action potentials preferentially in thalamocortical terminals of the prefrontal cortex, we made unilateral radiofrequency lesions in the anterior thalamus in five animals and performed sham lesions in three animals. After allowing 10-14 days for the thalamocortical projections to degenerate, we recorded neurons in the prefrontal cortex ipsilateral to the lesion $(n=8)$. As a control, we also recorded from neurons in the contralateral prefrontal cortex $(n=4)$ as well as from shamlesioned animals $(n=6)$. Responses in both these control groups were not significantly different from responses recorded from surgery-naïve animals. By contrast, as illustrated in Figure 4, layer $\mathrm{V}$ pyramidal neurons ipsilateral to the lesion showed an $\sim 80 \%$ reduction in sEPSCs induced by $\mathrm{nAChR}$ stimulation. It must be noted that these lesions, while large, spared portions of the thalamus, so nicotinicinduced responses were not expected to be completely eliminated.

\section{Suppression by $\mu$-Opioid Agonists}

Since the thalamic cell bodies are not present in the prefrontal slice preparation, we expected that manipulations that can reduce terminal excitability would decrease nAChR-induced glutamate release. For example, $\mu$-opioid 

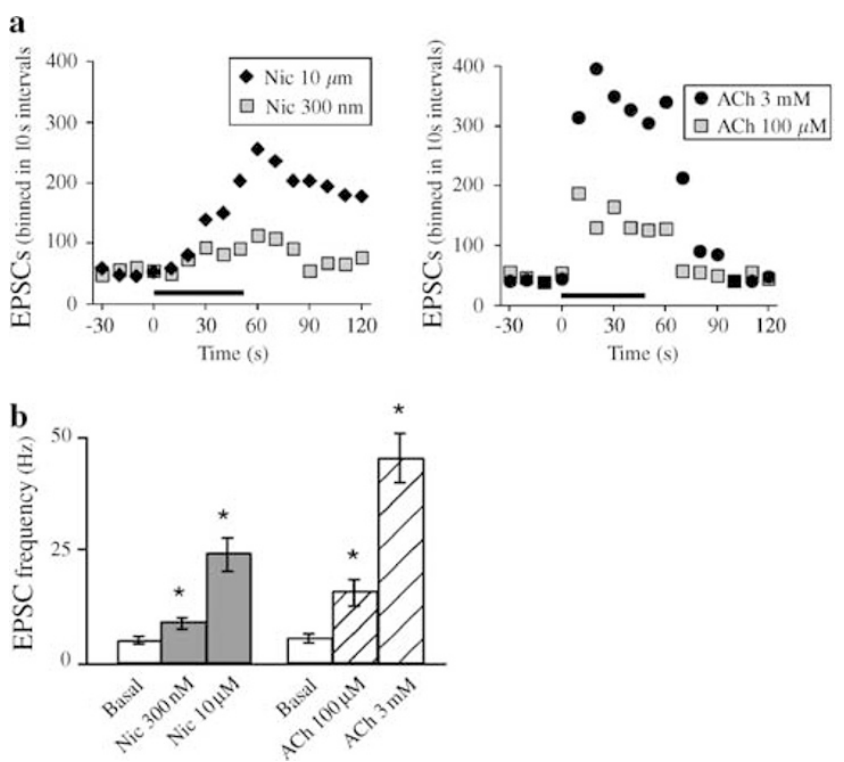

Figure 2 Time course and mean sEPSCs induced by different concentrations of nicotine and ACh. (a) Time course plots of sEPSCs induced in the neuron shown in Figure I by the different concentrations of nicotine and ACh (sEPSCs binned in $10 \mathrm{~s}$ intervals). (b) Mean peak responses to nicotine and $A C h$ from a group of neurons ( $n=5$; paired t-tests; $P \leqslant 0.01)$

receptors have been shown to reduce selectively the excitability of thalamocortical terminals in the prefrontal cortex (Marek and Aghajanian, 1998). We hypothesized that $\mu$-opioid-selective peptides would reduce sEPSCs induced by $\mathrm{nAChR}$ stimulation. As illustrated in Figure 5 , the $\mu$ opioid receptor agonist DAMGO $(3 \mu \mathrm{M})$ suppressed substantially sEPSCs induced by nicotine or ACh.

\section{Effects of Nicotine in Wildtype and $\beta_{2}$ AChR Knockout Mice}

The sensitivity to low concentrations of nicotine and ACh, and the prolonged response to nicotine as shown in Figures 1 and 2, suggests the involvement of the high-affinity (eg $\left.\alpha_{4} \beta_{2}\right)$ nAChRs (Zoli et al, 1998). In accordance with this hypothesis, we found near-complete suppression of nicotinic-induced sEPSCs by a competitive blocker of highaffinity nAChRs (DH $\beta \mathrm{E}: 10 \mu \mathrm{M}, 3 \mathrm{~min} ; n=5$; not shown), and no apparent induction of sEPSCs by an agonist of $\alpha_{7^{-}}$ subunit-containing nAChRs (Alkondon et al, 1997) (choline: $10 \mathrm{mM}, 30 \mathrm{~s} ; n=3$; not shown) in neurons that showed robust sEPSCs in response to nicotine. These preliminary pharmacological results add support to the hypothesis that the large increase in glutamate release is induced by highaffinity nicotinic receptors (Zoli et al, 1998). However, to more fully address this hypothesis, we examined responses in wildtype mice and $\beta_{2} \mathrm{nAChR}$ subunit knockout mice (Picciotto et al, 1995), as shown in Figure 6. In wildtype mice, nicotine and ACh induced robust increases in sEPSCs. By contrast, transgenic mice lacking the $\beta_{2}$ subunit of the $\mathrm{nAChR}$ failed to show nicotinic-induced sEPSCs.

As a control, we took advantage of previous work showing that serotonin $(5-\mathrm{HT})$ releases glutamate from thalamocortical terminals (Lambe and Aghajanian, 2001;
Marek et al, 2001). Unlike the differences observed for nicotinic stimulation, 5-HT-induced sEPSCs did not differ between wildtype and knockout mice (Figure 5). This control suggests that the loss of nicotinic-induced sEPSCs is because of the absence of the $\beta_{2}$-subunit-containing nAChR and does not result from a nonspecific abnormality in thalamocortical neurotransmission.

\section{DISCUSSION}

This study shows that $\mathrm{nAChR}$ stimulation can induce a large increase in glutamate release onto layer $\mathrm{V}$ pyramidal neurons. We explore the mechanism and receptor subunits underlying nAChR-induced glutamatergic sEPSCs, and show that this glutamate release is dependent on intact thalamocortical terminals. It was also shown that nicotinicEPSCs are sensitive to TTX and to blockade of high-voltageactivated calcium channels, suggesting that nAChRs induce glutamate release through a depolarization-mediated mechanism. Relatively low concentrations of nicotine or ACh are able to induce significant increases in sEPSCs, suggesting the involvement of high-affinity $\left(\mathrm{eg} \alpha_{4} \beta_{2}\right)$ nicotinic receptors. Accordingly, we found that nicotine-induced sEPSCs are absent in mice lacking the $\beta_{2} \mathrm{nAChR}$ subunit, supporting the dependence of this effect on high-affinity nAChRs. These data suggest that low levels of nicotine induce spike-dependent glutamate release from thalamocortical axons onto the output neurons of the prefrontal cortex and point to a previously undescribed mechanism through which nicotine can enhance prefrontal cortical activity.

In the present study, when thalamocortical terminals have degenerated following unilateral thalamic lesions, nAChRinduced sEPSCs were markedly decreased in the prefrontal cortex on the lesioned side but not in the control hemisphere nor in sham-lesioned animals. This $\sim 80 \%$ reduction strongly suggests that the relevant nAChRs are located in the terminal field of the thalamocortical projections. The result is consistent with work by Gil et al (1997) showing that nicotine modulates electrically evoked thalamocortical, but not corticocortical, glutamate release in superficial layers of the somatosensory cortex. It is also consistent with anatomical work showing that thalamic lesions decrease nicotine binding in the midlayers of the cortex (Prusky et al, 1987; Sahin et al, 1992; Lavine et al, 1997; Gioanni et al, 1999).

$\mu$-opioid receptors are also known to be present in thalamocortical terminals. Therefore, based on the involvement of thalamocortical terminals, we hypothesized that activation of $\mu$-opioid receptors would reduce nicotinicinduced glutamate release in the prefrontal cortex. The observed suppression by the $\mu$-opioid agonist, DAMGO, suggests an endogenous mechanism of modulation of nAChR-induced glutamate release. It also gives physiological evidence for the colocalization of nAChRs and $\mu$-opioid receptors on thalamocortical axon terminals, extending work done in a binding study which showed that both $\mu$ opioid and nicotine binding decreased in the mid-layers of the cortex following a thalamic lesion (Sahin et al, 1992).

Relatively low concentrations of nicotine $(300 \mathrm{nM})$ or $\mathrm{ACh}(100 \mu \mathrm{M})$ are able to induce significant increases in 
a
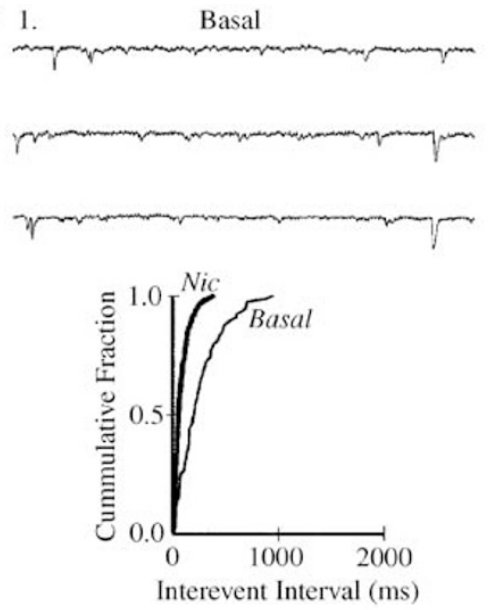

3.
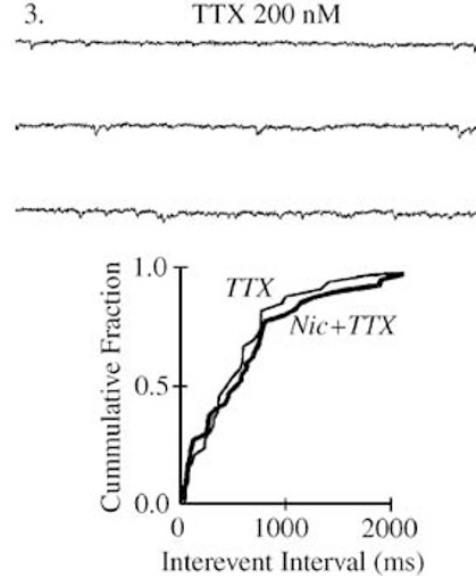

b

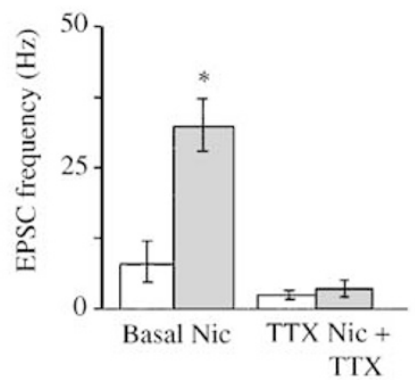

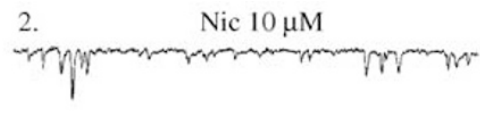
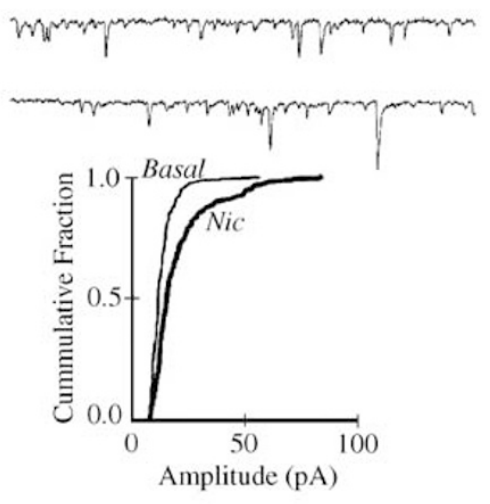

4. $\mathrm{TTX}+\mathrm{Nic} 10 \mu \mathrm{M}$
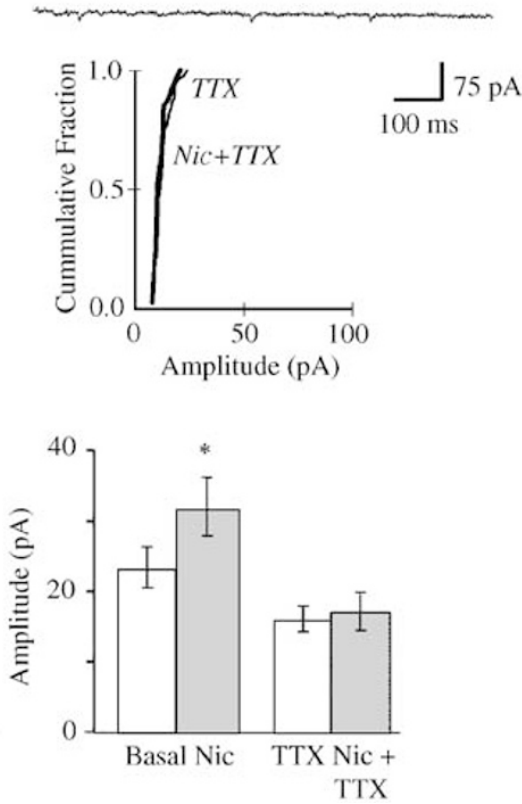

Figure 3 Nicotine increases the frequency of TTX-sensitive, spike-dependent sEPSCs. Spontaneous EPSCs recorded in layer $V$ of the prefrontal cortex have two components: TTX-insensitive mEPSCs and TTX-sensitive (spike-dependent) EPSCs. Nicotine increases the latter component of sEPSCs, which have been shown to have larger amplitude. (a) Sweeps in voltage clamp from a representative neuron show that nicotine produces a large, significant increase in sEPSC frequency and amplitude in the absence of TTX, as assessed by Kolmogorov-Smirnov analysis $(P<0.00 \mathrm{I})$, but does not produce an increase in frequency or amplitude of mEPSCs in the presence of TTX. (b) Mean sEPSC frequency and amplitude data from a group of neurons ( $n=6$; paired $t$-tests; $P \leqslant 0.01$ ).

sEPSCs. These concentrations are within the range for the blood level of nicotine observed in smokers (Armitage et al, 1975; Henningfield et al, 1983) and are well below the putative synaptic concentration of ACh, suggesting the possibility of extrasynpatic modulation (Zoli et al, 1999). The sensitivity of the terminals to relatively low concentrations of agonist and the prolonged nature of the response suggests the involvement of high-affinity nAChRs. Anatomical and knockout studies have suggested strongly that $\alpha_{4} \beta_{2}$ nAChRs predominate in the thalamus and thalamocortical projections (Wada et al, 1989; Picciotto et al, 1995;
Marubio et al, 1999; Han et al, 2000). These studies are congruent with the finding that nicotine-induced glutamate release from thalamocortical terminals was absent in $\beta_{2}$ subunit knockout mice. Although it is possible that the constitutive absence of the $\beta_{2} \mathrm{nAChR}$ subunit results in the development of abnormal thalamocortical circuitry in these mice, the 5-HT control suggests that this is not the case. This depolarization-mediated mechanism by $\alpha_{4} \beta_{2}$ nAChRs is reminiscent of that observed for nicotine-induced GABA release from inhibitory terminals in rat interpeduncular nucleus (Léna et al, 1993), ventrobasal thalamus (Léna and 

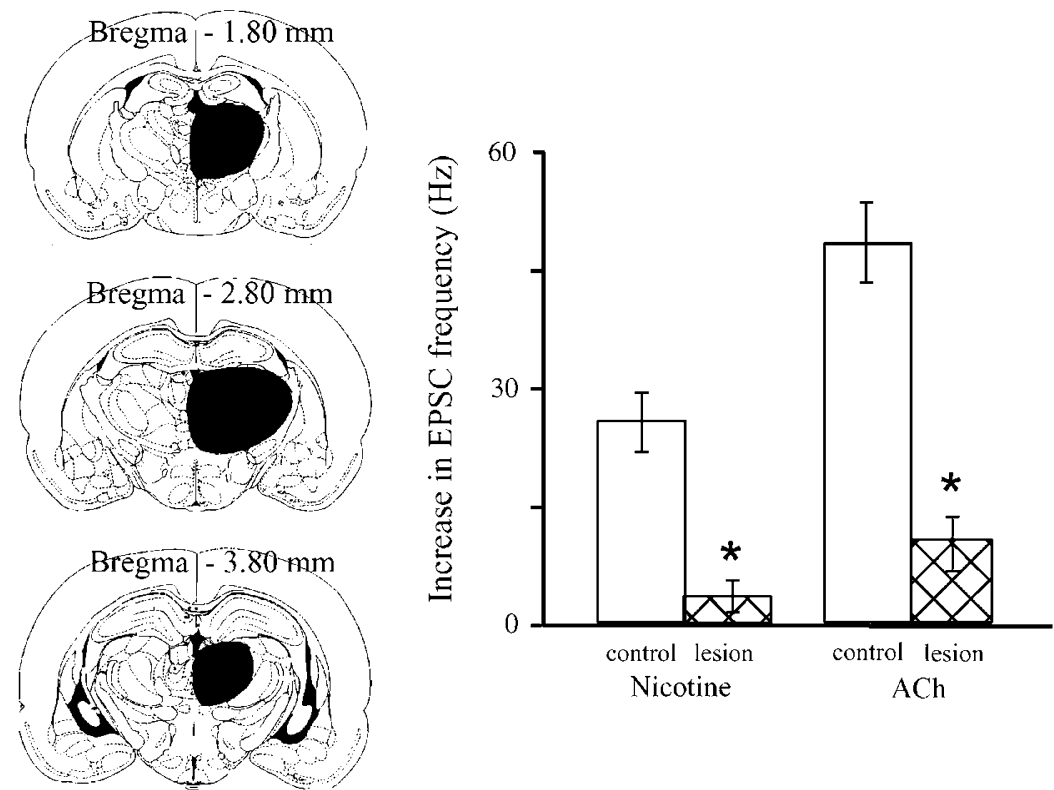

Figure 4 Thalamic lesions diminish the ability of nAChR stimulation to increase sEPSC frequency over baseline levels. The extent of the typical thalamic lesion is shown on the left. The bar graph on the right shows the effect of these lesions on the nAChR-induced increase in sEPSC frequency over baseline. Prefrontal neurons in the lesioned hemisphere $(n=8)$ show lower sEPSC frequency induced over baseline levels by nicotine $(I 0 \mu M$; unpaired $t=5.2$, $P<0.00 \mathrm{I})$ and $\mathrm{ACh}(3 \mathrm{mM}$; unpaired $t=4.9, P<0.00 \mathrm{I})$ compared to neurons $(n=10)$ from the contralateral hemisphere or from the cortex of shamlesioned controls. (Baseline sEPSC frequency: neurons from lesioned hemisphere, $9 \pm 3 \mathrm{~Hz}$; control neurons, $7 \pm 2 \mathrm{~Hz}$.)

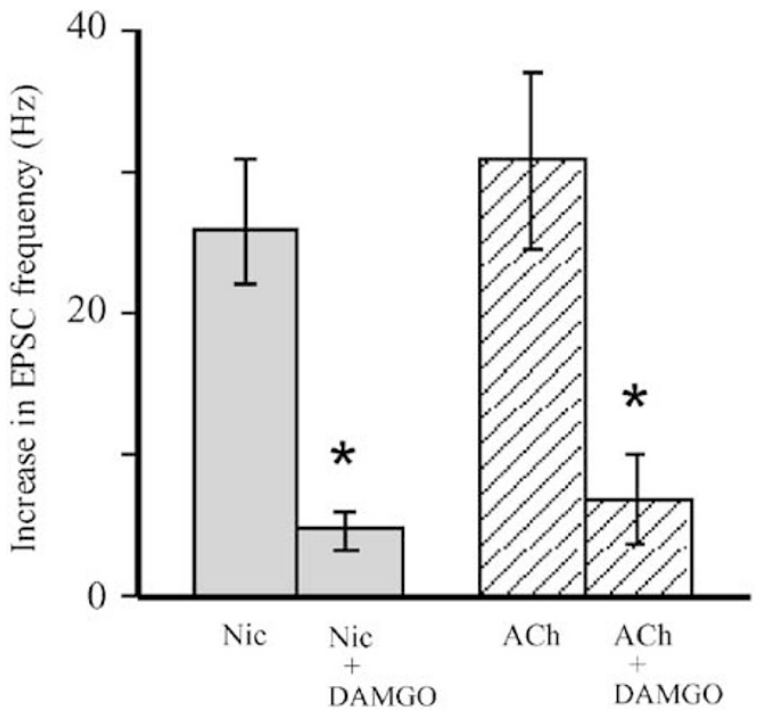

Figure 5 Activating $\mu$-opioid receptors, with DAMGO, suppress the frequency of sEPSCs induced over baseline levels by nicotine and ACh. A small peptide agonist of $\mu$-opioid receptors, DAMGO ( $3 \mu \mathrm{M}, 3 \mathrm{~min})$, lowered sEPSC frequency induced over baseline by nicotine ( $10 \mu \mathrm{M}$; paired $t=6.2, P \leqslant 0.002, \mathrm{df}=4)$ and ACh ( $3 \mathrm{mM}$; paired $t=5.8, P \leqslant 0.0 \mathrm{I}, \mathrm{df}=4)$. (Baseline sEPSC frequency: $9 \pm 2 \mathrm{~Hz}$.)

Changeux, 1997), and cerebral cortex (Alkondon et al, 2000).

The simplest mechanism to account for our data would be that nicotine induces a spike-dependent increase in glutamate release from thalamocortical terminals impinging directly upon layer $\mathrm{V}$ pyramidal cells. This model is consonant with the classical view that thalamocortical terminals are prone to the generation of local or 'ectopic' terminals action potentials (Gutnick and Prince, 1972; a

1. Basal

2. Nic $10 \mu \mathrm{M}$
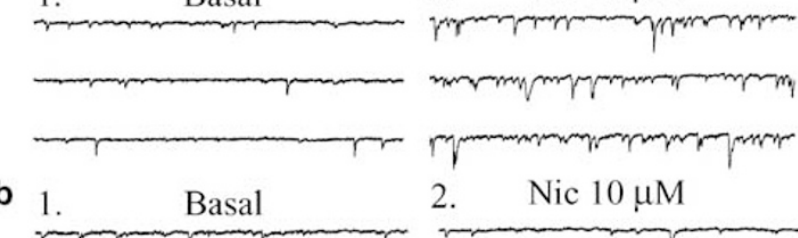

b 1 2. Nic $10 \mu \mathrm{M}$

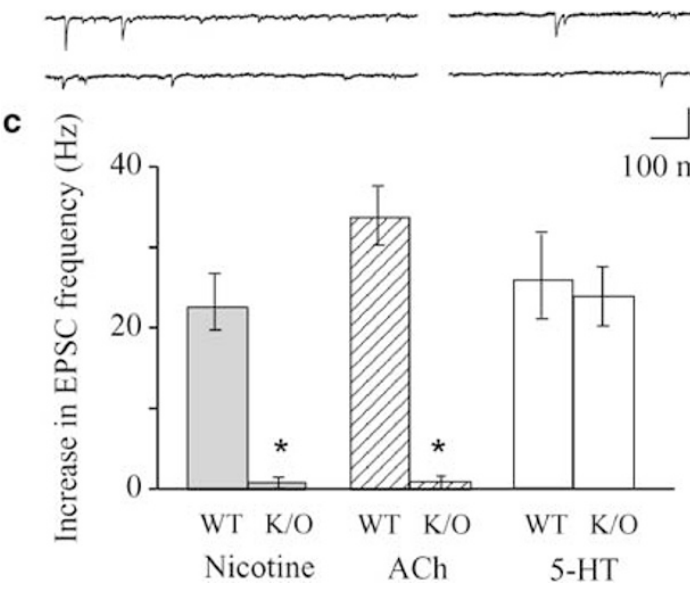

Figure 6 Induction of sEPSCs by nicotine or ACh depends on the presence of $\beta_{2} \mathrm{nAChR}$ subunits. Representative traces showing the effects of nicotine on sEPSC levels in layer $\vee$ pyramidal neurons from (a) wild-type mice and (b) transgenic mice lacking $\beta_{2}$ nAChRs. (c) Wild-type mice show robust sEPSCs induced over baseline levels by nicotine and ACh $(n=5)$. By contrast, nAChR stimulation fails to induce sEPSCs in transgenic mice lacking $\beta_{2} \mathrm{nAChR}(n=5)$ (nicotine: unpaired $t=7.8, P \leqslant 0.000 \mathrm{I}$; $\mathrm{ACh}$ unpaired $t=6.7, P \leqslant 0.00 \mathrm{I}$ ). Serotonin-induced sEPSCs serve as a control to show that glutamate release from thalamocortical terminals is otherwise unaffected in the knockout mice $(n=8)$. (Baseline sEPSC frequency: neurons from wild-type mice, $8 \pm 3 \mathrm{~Hz}$; neurons from $\beta_{2}$ nAChR knockout mice, $7 \pm 2 \mathrm{~Hz}$.) 
Rosen and Vastola, 1977; Noebels and Prince, 1978; Pinault and Pumain, 1989; Pinault, 1990). However, it should be noted that nicotine has been shown to enhance TTXinsensitive (ie spike-independent) release of glutamate in a number of brain regions (MacDermott et al, 1999); for example, in hippocampus (Gray et al, 1996), lateral geniculate (Guo et al, 1998), interpeduncular nucleus (McGehee et al, 1995), and olfactory bulb (Alkondon et al, 1996). Therefore, it could be suggested as an alternate hypothesis that direct calcium entry through nicotinic receptors on thalamocortical terminals could cause spikeindependent glutamate release, depolarizing prefrontal neurons via miniature EPSCs and causing them to fire and produce the sEPSCs we recorded. However, the lack of a large increase in nicotinic-induced mEPSCs in the presence of TTX (as shown in Figure 3), and the fact that none of the pyramidal neurons recorded were depolarized to spiking in the presence of nicotine, tend not to support this hypothesis. Channel subunit composition appears to be one major difference between the degree to which nAChRinduced glutamate release from terminals is mediated by depolarization or by direct calcium entry. The more highly calcium-permeable $\alpha_{7}$ nAChRs have been implicated in many examples of TTX-insensitive neurotransmitter release. By contrast, high-affinity $\beta_{2}$-containing nicotinic receptors appear to be able to facilitate transmitter release through both mechanisms (Léna et al, 1993; Léna and Changeux, 1997), the robustness of each type of release depending on characteristics of channel density or location which are not fully delineated.

A nicotinic induction of action potentials in the terminals of thalamocortical projections to the prefrontal cortex and anterior cingulate has ramifications for several aspects of normal cognitive function. Thalamic projections to the prefrontal cortex have been implicated in cortical arousal, attention and affective processing of sensory stimuli (Groenwegen and Berendse, 1994). The ability of prefrontal nAChR stimulation preferentially to activate these projections is congruent with the positive effects of nicotine on attention, information processing and affect (Levin and Simon, 1998; Stein et al, 1998; Dani, 2001), and its detrimental effects on sleep (Greenland et al, 1998). Interfering with stimulation of $\mathrm{nAChRs}$ in the prefrontal cortex results in disturbances in attention and working memory (Levin and Simon, 1998). The level of the endogenous transmitter, $\mathrm{ACh}$, has been shown to increase in the prefrontal cortex in many situations requiring enhancements in attention, ranging from presentation of novel stimuli to the accomplishment of an attentiondemanding task in the presence of distractions (Himmelheber et al, 2000; Passetti et al, 2000).

While previous studies have focused on the effects of nicotine in superficial layers of the cortex, the ability of nicotine to induce a large increase in spike-dependent glutamate release onto layer $\mathrm{V}$ pyramidal neurons has profound implications for cortical activation and output. Layer $\mathrm{V}$ neurons in the medial prefrontal cortex appear to be involved in determining the overall cortical tone with projections to the periaqueductal gray matter (Neafsey et al, 1986), as well as the monoamine-producing nuclei (Dalsass et al, 1981; Arnsten and Goldman-Rakic, 1984; Luppi et al, 1995; Hajós et al, 1998; Peyron et al, 1998). In particular, the medial frontal cortex is the primary source of cortical afferents to the dorsal raphe nucleus (Aghajanian and Wang, 1977; Hajós et al, 1998; Peyron et al, 1998) and the locus coeruleus (Cedarbaum and Aghajanian, 1978; Luppi et al, 1995), which respectively produce 5-HT and norepinephrine. The ability of nicotine to increase glutamate release onto layer $\mathrm{V}$ projection neurons has implications for various psychiatric conditions, including depression, where there are documented serotonergic and noradrenergic abnormalities together with an unusually high rate of nicotine use. Furthermore, recent work suggests that activity in the anterior cingulate encodes reward expectancy (Shidara and Richmond, 2002), and abnormalities in this region may play a role in addiction (Peoples, 2002).

Recent post-mortem work showed that people with autism have $\sim 70 \%$ less $\alpha_{4} \beta_{2}$ nAChR binding in the prefrontal cortex (Perry et al, 2001) and that the regulation of $\alpha_{4} \beta_{2}$ is altered in people with schizophrenia (Breese et al, 2000). Both autism and schizophrenia are distinguished by abnormal prefrontal cortical activation and difficulty engaging appropriate emotional responses to the external world (Weinberger and Berman, 1996; Rumsey and Ernst, 2000). It will be of interest to see whether these alterations in $\alpha_{4} \beta_{2}$ nAChRs contribute to these abnormalities.

\section{ACKNOWLEDGEMENTS}

We thank Dr Leonard Kaczmarek and Dr Patricia GoldmanRakic for valuable discussions and insights. Ms Nancy Margiotta contributed excellent technical assistance. This study was funded by NIMH (GA) and a Scottish Rite fellowship (EKL).

\section{REFERENCES}

Aghajanian GK, Marek GJ (1997). Serotonin induces excitatory postsynaptic potentials in apical dendrites of neocortical pyramidal cells. Neuropharmacology 36: 589-599.

Aghajanian GK, Wang RY (1977). Habenular and other midbrain raphe afferents demonstrated by a modified retrograde tracing technique. Brain Res 122: 229-242.

Alkondon M, Pereira EFR, Cortes WS, Maelicke A, Albuquerque EX (1997). Choline is a selective agonist of $\alpha 7$ nicotinic acetylcholine receptors in rat brain neurons. Eur J Neurosci 9: 2734-2742.

Alkondon M, Pereira EFR, Eisenberg HM, Albuquerque EX (2000). Nicotinic receptor activation in human cerebral cortical interneurons: a mechanism for inhibition and disinhibition of neuronal networks. J Neurosci 20: 66-75.

Alkondon M, Rocha ES, Maelicke A, Albuquerque EX (1996). Diversity of nicotinic acetylcholine receptors in rat brain. V. $\alpha$ bungarotoxin-sensitive nicotinic receptors in olfactory bulb neurons and presynaptic modulation of glutamate release. $J$ Pharmacol Exp Ther 278: 1460-1471.

Armitage AK, Dollery CT, George CF, Houseman TH, Lewis PJ, Turner DM (1975). Absorption and metabolism of nicotine from cigarettes. BMJ 4: 313-316.

Arnsten AFT, Goldman-Rakic PS (1984). Selective prefrontal cortical projections to the region of the locus coeruleus and raphe in the rhesus monkey. Brain Res 306: 9-18.

Berretta N, Jones RS (1996). A comparison of spontaneous EPSCs in layer II and layer IV-V neurons of the rat entorhinal cortex in vitro. J Neurophysiol 76: 1089-1100. 
Breese CR, Lee MJ, Adams CE, Sullivan B, Logel J, Gillen KM et al (2000). Abnormal regulation of high affinity nicotinic receptors in subjects with schizophrenia. Neuropsychopharmacology 23: 351-364.

Cedarbaum JM, Aghajanian GK (1978). Afferent projections to the rat locus coeruleus as determined by a retrograde tracing technique. J Comp Neurol 178: 1-16.

Dalsass M, Kiser S, Mendershausen M, German DC (1981). Medial prefrontal cortical projections to the region of the dorsal periventricular catecholamine system. Neuroscience 6: 657-665.

Dani JA (2001). Overview of nicotinic receptors and their roles in the central nervous system. Biol Psychiatry 49: 166-174.

Gil Z, Connors BW, Amitai Y (1997). Differential regulation of neocortical synapses by neuromodulators and activity. Neuron 19: 679-686.

Gioanni C, Rougeot C, Clarke PBS, Lepouse C, Thierry AM, Vidal C (1999). Nicotinic receptors in the rat prefrontal cortex: increase in glutamate release and facilitation of mediodorsal thalamocortical transmission. Eur J Neurosci 11: 18-30.

Gray R, Rajan AS, Radcliffe KA, Yakehiro M, Dani JA (1996). Hippocampal synaptic transmission enhanced by low concentrations of nicotine. Nature 383: 713-716.

Greenland S, Satterfield MH, Lanes SF (1998). A meta-analysis to assess the incidence of adverse effects associated with the transdermal nicotine patch. Drug Saf 18: 297-308.

Groenwegen HJ, Berendse HW (1994). The specificity of the 'nonspecific' midline and intralaminar thalamic nuclei. Trends Neurosci 17: 52-57.

Guo J-Z, Tredway TL, Chiappinelli VA (1998). Glutamate and GABA release are enhanced by different subtypes of presynaptic nicotinic receptors in the lateral geniculate nucleus. J Neurosci 18: 1963-1969.

Gutnick MJ, Prince DA (1972). Thalamocortical relay neurons: antidromic invasion of spikes from a cortical epileptogenic focus. Science 176: 424-426.

Hajós M, Richards CD, Székely AD, Sharp T (1998). An electrophysiological and neuroanatomical study of the medial prefrontal cortical projection to the midbrain raphe nuclei in the rat. Neuroscience 87: 95-108.

Han Z-Y, LeNovere N, Zoli M, Hill JA, Champtiaux N, Changeux JP (2000). Localization of $n A C h R$ subunit mRNAs in the brain of Macaca mulatta. Eur J Neurosci 12: 3664-3674.

Henningfield JE, Miyasato K, Jasinski DR (1983). Cigarette smokers self-administer intravenous nicotine. Pharmcol Biochem Behav 19: 887-890.

Himmelheber AM, Sarter M, Bruno JP (2000). Increases in cortical acetylcholine release during sustained attention performance in rats. Cog Brain Res 9: 313-325.

Lambe EK, Aghajanian GK (2001). The role of Kv.12-containing potassium channels in serotonin-induced glutamate release from thalamocortical terminals in rat frontal cortex. J Neurosci 21: 9955-9963.

Lavine N, Reuben M, Clarke PBS (1997). A population of nicotinic receptors is associated with thalamocortical afferents in the adult rat: laminal and areal analysis. J Comp Neurol 380: 175-190.

Léna C, Changeux J-P (1997). Role of $\mathrm{Ca}^{2+}$ ions in nicotinic facilitation of GABA release in mouse thalamus. J Neurosci 17 576-585.

Léna C, Changeux J-P, Mulle C (1993). Evidence for 'preterminal'nicotinic receptors on GABAergic axons in the rat interpeduncular nucleus. J Neurosci 13: 2680-2688.

Levin ED, Simon BB (1998). Nicotinic acetylcholine involvement in cognitive function in animals. Psychopharmacology 138: 217230.

Li X, Rainnie DG, McCarley RW, Greene RW (1998). Presynaptic nicotinic receptors facilitate monoaminergic transmission. J Neurosci 18: 1904-1912.
Luppi P-H, Aston-Jones G, Akaoka H, Chouvet G, Jouvet M (1995). Afferent projections to the rat locus coeruleus demonstrated by retrograde and anterograde tracing with cholera-toxin $B$ subunit and phaseolus vulgaris leucoagglutinin. Neuroscience 65: 119160.

MacDermott AB, Role LW, Siegelbaum SA (1999). Presynaptic ionotropic receptors and the control of transmitter release. Annu Rev Neuroscience 22: 443-485.

Marek GJ, Aghajanian GK (1998). 5-Hydroxytryptamine-induced excitatory postsynaptic currents in neocortical layer $\mathrm{V}$ pyramidal cells: suppression by $\mu$-opiate receptor activation. Neuroscience 86: 485-497.

Marek GJ, Wright RA, Gewirtz JC, Schoepp DD (2001). A major role for thalamocortical afferents in serotonergic hallucinogen receptor function in the rat neocortex. Neuroscience 105: 379392.

Marubio LM, del Mar Arroyo-Jimenez M, Cordero-Erausquin M, Léna C, Le Novere N, de Kerchove d'Exaerde A et al (1999). Reduced antinociception in mice lacking neuronal nicotinic receptor subunits. Nature 398: 805-810.

McCormick DA, Contreras D (2001). On the cellular and network bases of epileptic seizures. Annu Rev Physiol 63: 815-846.

McGehee D, Heath M, Gelber S, Devay P, Role LW (1995). Nicotine enhancement of fast excitatory synaptic transmission in CNS by presynaptic receptors. Science 269: 1692-1697.

Neafsey EJ, Hurley-Guis KM, Arvantis D (1986). The topographical organization of neurons in the rat medial frontal, insular and olfactory cortex projecting to the solitary nucleus, olfactory bulb, periaqueductal gray and superior colliculus. Brain Res 377: 261270.

Noebels JL, Prince DA (1978). Development of focal seizures in cerebral cortex: role of axon terminal bursting. J Neurophysiol 41: 1267-1281.

Passetti F, Dalley JW, O'Connell MT, Everitt BJ, Robbins TW (2000). Increased acetylcholine release in the rat medial prefrontal cortex during performance of a visual attentional task. Eur J Neurosci 12: 3051-3058.

Paxinos G, Watson C (1986). The Rat Brain in Stereotaxic Coordinates. Academic Press: New York.

Peoples LL (2002). Will, anterior cingulate cortex, and addiction. Science 296: 1623-1624.

Perry EK, Lee MLW, Martin-Ruiz CM, Court JA, Volsen SG, Merrit J et al (2001). Cholinergic activity in autism: abnormalities in the cerebral cortex and basal forebrain. Am J Psychiatry 158: 10581066.

Peyron C, Petit J-M, Rampon C, Jouvet M, Luppi P-H (1998). Forebrain afferents to the rat dorsal raphe nucleus demonstrated by retrograde and anterograde tracing methods. Neuroscience 82: 443-468.

Picciotto MR, Zoli M, Léna C, Bessis A, Lallemand Y, LeNovere N et al (1995). Abnormal avoidance learning in mice lacking functional high-affinity nicotine receptor in the brain. Nature 374: 65-67.

Pinault D (1990). Antidromic firing occurs spontaneously on thalamic relay neurons: triggering of ectopic action potentials by somatic intrinsic burst discharges. Neuroscience 34: 281-292.

Pinault D (1995). Backpropagation of action potentials generated at ectopic axonal loci: hypothesis that axon terminals integrate local environmental signals. Brain Res Rev 21: 42-92.

Pinault D, Pumain R (1989). Antidromic firing occurs spontaneously on thalamic relay neurons: triggering of somatic intrinsic burst discharges by ectopic action potentials. $\mathrm{Neu}$ roscience 31: 625-637.

Prusky GT, Shaw C, Cynader MS (1987). Nicotine receptors are located on lateral geniculate nucleus terminals in cat visual cortex. Brain Res 412: 131-138. 
Rosen AD, Vastola EF (1977). Antidromic activity in visual radiation during evoked cortical responses. J Neurophysiol 40: 9-14.

Rumsey JM, Ernst M (2000). Functional neuroimaging of autistic disorders. Ment Retard Dev Disabil Res Rev 6: 171-179.

Sahin M, Bowen WD, Donoghue JP (1992). Location of nicotinic and muscarinic cholinergic and $\mu$-opiate receptors in rat cerebral neocortex: evidence from thalamic and cortical lesions. Brain Res 579: 135-147.

Schwarztkroin PA, Mutani R, Prince DA (1975). Orthodromic and antidromic effects of a cortical epileptiform focus on ventrolateral nucleus of the cat. J Neurophysiol 38: 795-811.

Shidara M, Richmond BJ (2002). Anterior cingulate: single neuronal signals related to degree of reward expectancy. Science 296: 1709-1711.

Sidach SS, Mintz IM (2000). Low-affinity blockade of neuronal Ntype $\mathrm{Ca}^{2+}$ channels by the spider toxin $\omega$-agatoxin-IVA. $J$ Neurosci 20: 7174-7182.

Stasheff SF, Hines M, Wilson MA (1993). Axon terminal hyperexcitability associated with epileptogenesis in vitro. I. Origin of ectopic spikes. J Neurophysiol 70: 961-975.

Stein EA, Pankiewicz J, Harsch HH, Cho J-K, Fuller SC, Hoffmann RG et al (1998). Nicotine-induced limbic cortical activation in the human brain: a functional MRI study. Am J Psychiat 155: 1009-1015.

Vidal C, Changeux J-P (1993). Nicotinic and muscarinic modulations of excitatory synaptic transmission in the rat prefrontal cortex in vitro. Neuroscience 56: 23-32.

Wada E, Wada K, Boulter J, Deneris E, Heinemann S, Patrick J et al (1989). Distribution of $\alpha 2, \alpha 3, \alpha 4$, and $\beta 2$ neuronal nicotinic receptor subunit mRNAs in the central nervous system: a hybridization histochemical study in the rat. J Comp Neurol 184: 314-335.

Weinberger DR, Berman KF (1996). Prefrontal function in schizophrenia: confounds and controversies. Philos Trans $R$ Soc London 351: 1495-1503.

Wong TP, Marchese G, Casu MA, Ribeiro-da-Silva A, Cuello AC, De Koninck Y (2000). Loss of presynaptic and postsynaptic structures is accompanied by compensatory increase in action potential-dependent synaptic input to layer $\mathrm{V}$ neocortical pyramidal neurons in aged rats. J Neurosci 20: 8596-8606.

Zoli M, Jansson A, Sykova E, Agnati LF, Fuxe K (1999). Volume transmission in the CNS and its relevance for neuropsychopharmacology. Trends Pharmacol Sci 20: 142-150.

Zoli M, Léna C, Picciotto MR, Changeux JP (1998). Identification of four classes of brain nicotinic receptors using $\beta_{2}$ mutant mice. J Neurosci 18: 4461-4472. 